\title{
Results comparison of alkali-reactivity tests for same aggregates, using a kinetic model \\ GONZALEZ, Luis Mayor ${ }^{1 a^{*}}$, SANTOS SILVA, António ${ }^{2 b}$, JALALI, Said ${ }^{1 \mathrm{C}}$ \\ ${ }^{1}$ Department of Civil Engineering, University of Minho, Guimarães, Portugal \\ ${ }^{2}$ Materials Department, National Laboratory for Civil Engineering, Lisboa, Portugal \\ a' Imgonzalez@mail.telepac.pt, ${ }^{b}$ ssilva@Inec.pt, ${ }^{c}$ said@civil.uminho.pt
}

Keywords: Expansion tests, reactivity, alkali-silica reaction, aggregates

\begin{abstract}
A kinetic based comparison between expansion tests for alkali-aggregate reactivity was carried out deriving critical rates from test criteria, in an earlier paper. The present paper checks the assumptions and models of that earlier comparison against results with real aggregates varying in alkali reactivity. Using the same approach, for each aggregate, expansion rates for three expansion tests were estimated, corrected for alkalinity and depicted as an Arrhenius plot. The relationship used data from NF P18590, ASTM C 1260 and ASTM C 227 expansion test-methods and shows linear Arrhenius plots for several aggregates, aligned almost parallel to the line obtained for test criteria. Aspects related to the different experimental conditions on test-methods and their effects are discussed. The proposed conclusion is that both standards and aggregate results, in the given conditions, are not inconsistent from the kinetic point of view. Some suggestions are made for improving the accuracy of the relationship obtained.
\end{abstract}

